
\title{
25 Research Soure \\ Efficacy of combined education to promote self efficacy and self-care oral health behaviors of students: a randomized controlled trial
}

\section{Zahra Sadat Hashemi}

Arak University of Medical Sciences

Mahboobeh khorsandi ( $\nabla$ dr.khorsandi@arakmu.ac.ir)

Arak University of Medical Sciences https://orcid.org/0000-0002-1680-5124

Mohsen Shamsi

Arak University of Medical Sciences

Rahmatollah Moradzadeh

Arak University of Medical Sciences

Research article

Keywords: Oral and dental health, Students, Combined methods, Self-efficacy, Self-care behavior

Posted Date: June 19th, 2020

DOI: https://doi.org/10.21203/rs.3.rs-21071/v2

License: (a) (i) This work is licensed under a Creative Commons Attribution 4.0 International License. Read Full License

Version of Record: A version of this preprint was published at BMC Oral Health on July 13th, 2021. See the published version at https://doi.org/10.1186/s12903-021-01693-y. 


\section{Abstract}

Background: In order to prevent oral diseases, the use of appropriate educational methods at childhood is one of the most important strategies for the public health. Therefore, the present study aimed to evaluate the effect of training through animations and games on oral health self-efficacy and self-care behaviors among 6-12-aged students.

Methods: In this interventional study, 82 students were selected based on cluster random sampling including 38 for the case and 44 for control group). The case group received four sessions of combined learning per week including animations and games while the control group received routine school education. The data were collected in six domains including demographics, self-care, knowledge, attitude, behavior and self-efficacy before and 5 months after the intervention using a questionnaire. SPSS version 20 was used for data analysis.

Results: Five months after the intervention, the mean score of self-care, self-efficacy, behavior increased from 3.8 to $4.8,36.8$ to 48.9 , and 17.07 to 18.29 , respectively indicating a significant change $(p<0.05)$. However, no significant change was reported in these variables in the control group $(p>0.05)$

Conclusion: The use of combined methods for oral health self-care education can positively influence the students' performance and self-efficacy

\section{Backgroud}

Despite major advances in oral and dental health in many countries, oral and dental health problems are still a global challenge with a larger magnitude in populations with a weak socioeconomic status (1). Early loss of teeth, in addition to undesirable effects on facial aesthetics and pronunciation, may result in inadequate growth and nutritional problems due to chewing difficulties. Moreover, untreated oral and dental infections can cause valvular heart disease, digestive problems, and rheumatic heart disease (2).

Based on the national survey in 2015, the dmft index of the children aged 6 was 5.84 in a national level of Iran (1). In addition, DMFT was identifed (5.4 \pm 2.83 ) in Arak (2). Further, the DMFT index of 12-year-old children was 2.09 in a national level (3). However, the WHO emphasized that the DMFT index of 12-yearold children should be less than 1 and $90 \%$ of the 6 -year-old children should have completely healthy teeth by 2010 (3).

In addition, 6-12-aged children are in a priority based on oral health programs due to the high prevalence of caries and the significance permanent growth of teeth. Any change or improvement in the behavior of this group can have long-term and significant effects on their future. Some researchers believe that raising knowledge in this age group is the only way to improve oral health for future (4). To prevent oral diseases, the implementation of health interventions at schools may have significant long-standing effects on the health behaviors of future generations due to their roles in structuring and forming habits, beliefs, and insight among students (5). In addition, it is considered as an effective and efficient method 
for communicating health messages to the students' families and the society to promote a healthy lifestyle (6). School children can have good dental health in adult file when they maintainthis habit in school. Thus, the pattern of regular dental attendance in early life is vailable after the school age (7). Schools are considered as important places for establishing a strong link between health and education (8). Health education among school children plays a signifinat role for preventing the problems related to oral health (9). In this regard, educating oral health is regarded as the first step for preventing oral diseases in order to reduce socio-demographic differences, as well as providing equal opportunities for oral health, which results in promoting the measures which are essential for increasing the quality of life among population. In addition, oral health education should considere food hygiene such as controlling the consumption of cariogenic foods with a high content of carbohydrates, which is important for avoiding the development of dental caries (10) .

Oral health education seeks to enhance oral health through educational means, especially through providing information to enhance oral health knowledge for accommodating a healthier lifestyle, and changing attitudes and pleasant behaviors (11). Traditional health education instruments such as lectures, demonstration, and models are used in most of the programs used for promting health at schools. Based on the results, these tools play a slight or short-term effect on children. In addition, some studies indicated that these programs play a trivial role on the cleanliness of teeth among children.(9). In general, health education programs are used for creating new behaviors, as well as maintaining healthy behaviors which can promote individual and community health(12). In this regard, education and entertainment should be integrated to create a happy context for learning among children(9).

Result of Zulkarnian indicated that cartoon animation can increase the level of KAP score more than that of the conventional method (13). Compared to traditional methods in which texts and static graphics are used for training, the students are exposed to dynamic images and motion pictures in the animation method, which gives a new meaning and concept to literacy and education (14) . Further, games, as a means of entertainment, can be used for education. During games, the children achieve valuable experiences and learn new things willingly without pressure (15) .

It is recommended that health experts emphasize self-efficacy as the most important predictor of oral and dental health behaviors (16),(17). Self-efficacy refers to a person's belief that they can do successfully the behavior necessary to produce the desired outcomes. It is considered as the belief in her or his ability to do and succeed in a particular task (18). Some studies reported the translation of the theory of self-efficacy into the field of oral hygiene by focusing on positive relations to plaque levels, brushing frequency, and loss to periodontal follow-up (18). Self-efficacy predicts a range of health behaviors including oral self-care (10). Efficacy, in turn, has four sources including mastery experiences, observing learning, verbal persuasion, and physiological and emotional states during behavioral opportunities(19). Lack of self-regulatory skills are related to a disinclination to change health behaviors such as deficits in self-efficacy, planning, and action control (10). 
In self-care programs, the person is supposed to know his/her own unfavorable condition, set objectives and make plans to reach the favorable condition, become committed to execute the plan, be aware of the consequences of executing the self-care program, and learn the required skills for behavior change.To the best of our knowledge, no program has focused on promoting self-regulation and self-efficacy oral health with animation- and game-based learning in Iran. In this study, a combination of training methods was used to promote knowledge, attitude, and self-efficacy and behavior of the students. Further, a selfcare program was used as a complement for ensuring order and stability in the behavior. The present study aimed to use a combined training package for promoting oral and dental health in students through applying a self-care program to ensure the continuity of oral and dental health behaviors and teach oral and dental self-care skills in a practical manner.

\section{Methods}

In the present interventional study, 82 primary school students were selected based on multi-stage cluster sampling. After receiving the required clearance for conducting the research and coordination with local authorities, two girl schools and two boy schools were randomly selected from governmental schools. Each grade was considered a cluster and 4 participants were randomly selected from each grade using class rosters. In the next stage, using simple randomization, one boy school was selected as the case school and another school was considered as the control school. The same process was applied to girl schools. The sample size, based on the results of the previous studies, was $\alpha=0.01$ and $\beta=0.1$, and the attrition of $20 \%$ was 48 participants in the case group and 48 in the control group (20). However, 14 students did not complete the study. Thus, the data for 82 students including 38 in the case group and 44 in the control group were considered for analysis. The inclusion criteria were willingness to participate in the study, having the consent form signed by parents, and studying in the primary schools of $X$ city . The exclusion criteria were withdrawal from the study, missing more than one educational session, and immigration from $X$ city.

The data collection tool was a researcher-made questionnaire containing questions on self-care, knowledge, attitude, behavior, and self-efficacy, which was developed based on the questionnaires designed by Mohammadi Zeidi et al. (21) and Samiee Roudi et al. (22). The content validity of the questionnaires (CVI and CVR) was evaluated by asking a panel of experts including 10 experts in health education, school health, oral and dental health, and dentists. A CVR of above 0.62 was considered as acceptable. Regarding $\mathrm{CVI}$, the experts evaluated each item in terms of relevance, clarity, and simplicity Based on the results, all were considered as acceptable since all values were above 0.79 (23). The reliability of the questionnaire was measured through the Cronbach's alpha coefficient in 30 students aged 6-12 years whose demographic characteristics were similar to those of the study population using the Stata 14 software (24) .

The questionnaire was designed in six sections. The variables like age, grade, sex, height, weight, etc. were collected in the demographics section. Private and personal questions were avoided in this part. The self-care section included 5 yes-no questions, and "I don't know" as answers. Each correct answer 
received a score of 1 and a score of 0 was given to wrong and "I don't know" answers. The total score of this section was 5 . I clean my mouth and teeth myself ( $a$. Yes, b. No. c. I don't know). The knowledge section contained 10 questions with three-choice answers For example, what is the best way to clean the space between your teeth? a. Toothbrush, b. Dental floss, c. Mouthwash). A score of 1 was given to correct answers, totaling a score of 10 . The attitude section had 13 questions in a 5-point Likert scale from 1 to 5 with a total score of 65 . For example, l think eating milk is very important for dental health ( 1 totally agree, I agree, It doesn't matter,I disagree, I completely disagree) Behavior was assessed with 8 questions in a 5-point Likert scale with a total score of 32. For example, I wash my mouth after eating sweets and food (Always, Most of the time, Sometimes, Rarely, Never). In adition, fourteen questions were used to assess self-efficacy in a 5-point Likert scale, scoring a total of 70 points. In each of the following situations, how sure are you that you can clean your teeth?When you are very tierd ( I'm not at all sure, I'm a little confident, I'm pretty sure, I'm pretty sure, I'm pretty sure). The questionnaires were completed in the form of interviews to explain more details to the students and provide appropriate answers. After coordination with school principals and conducting a pretest, two schools were randomly selected as the cases and received training in 4 45-60-min sessions (Table 1). The schools considered for control received routine school training. This study caused no conflicts of interest for any person or organization.

In this study, watching animations was used as a substitute for traditional training techniques. Exercising and recalling the learned material during games in a simple and child-friendly atmosphere causes an emotional arousal in children. Children's involvement in practical education of oral and dental health behaviors, their success in correct performance, and regular display of the behavior based on a plan can be considered as the sources for self-efficacy. Moreover, positive feedback and encouragement of the instructors and parents provide a source of verbal persuasion for children. In this study, the students were taught about nutrition and its effect on oral health.

Written parental informed consent, as well as written child assent, was obtained from all students participating in this study. In addition, the training materials such as the booklets and CD (Animation ) were given to the control group. This study was registered under the ethics code of IR.ARAKMU.REC.1395.446.

Pre and post-intervention data were collected using a questionnaire (Apendix 1 ) and entered into SPSS version 20. The questionnaires were completed in the form of interviews to explain more details to the students and provide appropriate answers. The Kolmogorov-Smirnov test was applied to check normal data distribution and proper statistics were used accordingly. Chi square test, paired and independent $t$ test, Mann-Whitney U test, and Wilcoxon signed-rank test were used for statistical analysis.

\section{Results}

The results indicated that gender, parents' education, and number of family members had a similar distribution between the two groups (Table 2). The mean age of the subjects was $9.6 \pm 1.9$ years in the control group and $9.4 \pm 1.8$ years in the case group (Table 3 ). After the intervention in the case group, the 
mean scores of self-care, knowledge, attitude, behavior, and self-efficacy increased from $3.8 \pm 0.96$ to $4.8 \pm 0.3,6.7 \pm 2.5$ to $9.4 \pm 0.9,55.1 \pm 12.5$ to $61.5 \pm 4.8,17.07 \pm 5.61$ to $21.21 \pm 5.07$, and $36.8 \pm 11.6$ to $48.9 \pm 10.8$ respectively, which were all significant. In control and intervention groups, by using of Mann-Whitney $U$ test, scores changes of selfcare, knowledge, attitude, behavior, and self-efficacy in before and post intervention between girls and boys were not be statistically significant $(P>0.05)$. Furthermore, in control and intervention groups, the scores changes of selfcare, knowledge, attitude, behavior, and self-efficacy in before and post intervention by father's education, mother's education and birth rank were not be statistically significant ( $P>0.05)$. In addition, in control and intervention groups, with spearman correlation test, significant correlations were not observed between age, and Number of family members with scores changes of selfcare, knowledge, attitude, behavior, and self-efficacy in before and post intervention $(p>0.05)$.

\section{Discussion}

The present study aimed to evaluate the efficacy of combined education to promote self efficacy and self-care oral health behaviors among the students.Based on the results, no difference was observed between the intervention and control groups in terms of parents' level of education, which indicates the homogeneity of the groups.

In addition, a significant increase was observed in the mean score of self-care in the case group after the educational intervention compared to baseline, indicating the positive effect of Planning on improving self-care. The results are consistsent with those of Mohammad-Zeidi et al (21) on the effectiveness of an educational intervention based on the stages-of-change model in improving oral health self-care behaviors among 160 male and female elementary students in Qazvin. Further, Mohammadi Zeidi et al. (25) studied the effect of motivational interviewing of oral self-care behaviors among high school students ion Qazvin and found a significant change in the mean score of behavioral intention in the case group after the intervention. In this study, health teachers were asked to teach students. The findings indicated the significance of training teachers to teach self-regulation skills in class (12). According to the National Oral Health Care Program, students follow the suit when teachers brush their teeth, which becomes a daily exercise routine. In addition, it can enhance the link

between education and healthy habits since it can shape the individual's way of life and personality. School teachers can set the ground for dental health education and screening for any gross deposit of food and calculus, which is confimed to be a more effective way of imparting and educating children for good oral hygiene (7)

In this study, attempts were made to engage parents for reinforcing children oral health behavior by providing booklet and CD animation. Family and other "important others" play a role in developing selfcare habits among children and young people (26).

Health education is a widely accepted and practiced approach for preventing oral and dental diseases. Further, it is considered as the process which transfers the knowledge and skills required for imporving 
the quality of life (27). In this study, knowledge significantly increased after the intervention in the case group, which is line with the results of the studies conducted by Goudarzi (28) and Samiee Roudi (22). The mean score of knowledge increased after the intervention in the control group although the difference was smaller compared to the case group. The reason for this difference could be the routine education provided by school health instructors according to the educational curriculum. Mamata Hebbal (29) found a significant change in knowledge in the control group after the intervention due to its Hawthorne effect.

Further, a significant change was reported in the score of knowledge between the case and control groups after the educational intervention, which could indicate the greater effect of educational interventions delivered through animation and game. Moreover, having knowledge about a particular subject affects the person's behavior in this regard (30) .

To have a healthy lifestyle, training children early forms their attitude and promotes healthy behaviors (31).

Dental caries preventive behavior is significantly and positively related with knowledge and attitude so that the increase in knowledge and attitude results in adopting oral health-related behaviors (11).

The present study assessed the students' attitude, i.e. their positive or negative thoughts about oral health behaviors. One of the assumptions in this study was a significant change in the mean score of attitude in the case group after the intervention, which was confirmed by the results. The results of Goudarzi et al. (28) and Mohd Zulkarnain Sinor et al. (13) are in line withthose in the present study.

The learner's practical engagement in the subject and interaction can help them recall $60 \%$ of the learned behavior (19). In this study, the mean score of behavior increased significantly after educational intervention by using a combination of games and animation and conducting the self-care program, compared to baseline in the intervention group, which is consistent with the results of Mohamadkhah et al. in Chabahar elementary students (25), Neha Singh et al.(32), and Goudarzi et al. (28) which reported significant changes in the score of behavior after the intervention.

Bandora considers self-efficacy as an essential factor in changing behavior which improves through mastery over the behavior. Therefore, self-efficacy improves an active and successful participation in a behavior (19). Finally, the mean score of self-efficacy increased significantly in the case group after the intervention, which is consistent with the result of Mohammad-Zeidi et al. (25).

\section{Limitation:}

The present study is suffereing from some limitations. For example, conducting the educational intervention in all 6 primary grades, in addition to the difficulties in coordination for participation of all students, interfered with their routine classes, especially in grades five and six, due to an overcrowded curriculum. Due to high costs, it was not possible for the researcher to prepare the animation, and the 
available animations which were in accordance with the needs of the study group were used for educational intervention. Finally, it was not possible to ask a nurse or dentist to attend the dental examination at the school, and only a check-up was taken by a health educator. Therefore, we were unable to report the dental indicators.

\section{Conclusion}

Based on the results, the use of combined training and age-appropriate methods including animation and game which were used to promote self-efficacy played a significant role in improving the oral health behaviors and self-efficacy in the students, in addition to improving their knowledge and changing their attitude towards the importance of oral health. The school environment, with its unique time and place structure, has a great potential for educational interventions. School-based oral health programs is more effective when education is integrated with active prevention and/or treatment programs. Supporting the oral health of future generations is considered as a commitment which should be shared by parents, teachers, school administrators, and all health professionals.

Due to multifactorial aspect of oral health, it is recommended that health education models which incorporate environmental and policy factors such as PRECEDE-PROCEED model be used to promote dental oral health.

\section{Declarations}

\section{Ethics approval and consent to participate:}

Ethics approval was received from Arak University of Medical Sciences (ethical code:

IR.ARAKMU.REC.1395.446). This study was registered in the Iranian Registry of Clinical Trials (IRCT2017042133565N1). Informed consent was obtained from all participants in this study.

Consent for publish: The manuscript does not include any individual personal data in any form.

Availability of data and material: The datasets used and.or analyzed during the current study are available upon reasonable request from the corresponding author.

Competing interests: The authors declare that they have no conflict of interests.

Funding: the vice chancellor for Research in the University for supported this project.

Authors' contributions: $\mathrm{Hz}$ and $\mathrm{KM}$ and $\mathrm{SH} \mathrm{M}$ and $\mathrm{M} \mathrm{R}$ designed the study. $\mathrm{Hz}$ performed the intervention. $\mathrm{M} \mathrm{R}$ analyzed the data. $\mathrm{Hz}$ and $\mathrm{K} \mathrm{M}$ and $\mathrm{SH} \mathrm{M}$ and $\mathrm{M} \mathrm{R}$ wrote the paper with input.All authors read and approved the manuscript.

\section{Acknowledgement}


The authors would like to thank the authorities of the Department of Education in Markazi Province and XCounty, as well as the teachers, parents, and students who participated in this study for their sincere cooperation.

This study adheres to Consort guidelines. See attached checklist.

\section{Abbreviations}

DMFT.dmft: Decayed, Missing, and Filled Teeth

CVR:Content Validity Ratio

CVI:Content validity Index

WHO:World health organization

\section{References}

1. Babaei A, Pakdaman A, Hessari $H$, Shamshiri AR. Oral health of 6-7 year-old children according to the Caries Assessment Spectrum and Treatment (CAST) index. BMC oral health. 2019;19(1):20.

2. Shahnazi H, Hosseintalaei M, Ghashghaei FE, Charkazi A, Yahyavi Y, Sharifirad G. Effect of educational intervention on perceived susceptibility self-efficacy and DMFT of pregnant women. Iranian Red Crescent Medical Journal. 2016;18(5).

3. Khoshnevisan M, Ghasemianpour M, Samadzadeh H, Baez R. Oral health status and healthcare system in IR Iran. Journal of Contemporary Medical Sciences. 2018;4(3).

4. Shakerian M, Sardari F, Kordafshari T. The relationship between knowledge of oral health-related issues and the DMFT index in 12-year-old students in Rafsanjan, Iran, in 2016. Journal of Occupational Health and Epidemiology. 2016;5(1):31-7.

5. Hajimiri K, Sharifirad G, Hasanzade A. The effect of oral health education based on health belief model in mothers who had 3-6 year old children on decreasing dental plaque index in Zanjan. J Adv Med Biomed Res. 2010;18(72):77-86.

6. Z S-M. Oral Health among Iranian Preadolescents: A School-Based Health Education Intervention. http://ethesishelsinkifi/. 2010.

7. Parmar P, Radha G, Rekha R, Pallavi S, Nagashree S. Promoting oral hygiene and health through school. International Journal of Oral Health Sciences. 2016;6(2):70.

8. Khoshnevisan MH, Pakkhesal M, Jadidfard MP, Godarzi Nejad G. School-Based Oral Health Promotion: A Thorough Review. Journal of dental school 2017;35(4):143-9.

9. Malik A, Sabharwal S, Kumar A, Samant PS, Singh A, Pandey VK. Implementation of Game-based Oral Health Education vs Conventional Oral Health Education on Children's Oral Health-related 
Knowledge and Oral Hygiene Status. International journal of clinical pediatric dentistry. 2017;10(3):257.

10. Zhou G, Sun C, Knoll N, Hamilton K, Schwarzer R. Self-efficacy, planning and action control in an oral self-care intervention. Health Education Research. 2015;30(4):671-81.

11. Rashidi Birgani H, Niknami S. Effect of Oral Health Education on Adoption of Dental Caries Preventive Behaviors among Elementary Students Using Combined Training. Health Education and Health Promotion. 2019;7(1):1-7.

12. Al-Qahtani SM, Razak PA, Khan SD. Knowledge and Practice of Preventive Measures for Oral Health Care among Male Intermediate Schoolchildren in Abha, Saudi Arabia. International journal of environmental research and public health. 2020;17(3):703.

13. M Z. Comparison between Conventional Health Promotion and Use of Cartoon Animation in Delivering Oral Health Education. International Journal of Humanities and Social Science. 2011;1(169-174).

14. Z K, S K, A K. Effect of teaching based on animation technique, dynamic and static graphics on learning science lessons. Quarterly Technology Education and Learning. 2015;2(5):67-80.

15. Aazami M JA. the rolet of game on academic achievement (Language learning) of elementary Third grade children Tehran city in 2006-2007 Journal of Behavioral Sciences. 2006:9-30.

16. SMM H, B M, AR S, L R. Assessment of oral - dental health status: using Health Belief Mode(HBM) in first grade guidance school students in Hamadan. Journal of health Science Jondishapoor. 2012;4(3):66-75.

17. RR K, F I, SZ H. Survey of oral health behaviors and its associated factors in female students of primary schools in Zabol based on health belief model. Zahedan university of medical science. 2011:33-41.

18. Chen KJ, Gao SS, Duangthip D, Lo ECM, Chu CH. Early childhood caries and oral health care of Hong Kong preschool children. Clinical, cosmetic and investigational dentistry. 2019;11:27.

19. Williams DM, Rhodes RE. The confounded self-efficacy construct: Conceptual analysis and recommendations for future research. Health psychology review. 2016;10(2):113-28.

20. M SM, T D, J A. Oral health education program among pre-school children: an application of healthpromoting schools approach. Health Promotion Perspectives. 2016;6(3):164-70.

21. I MZ, P P, B MZ. Effectiveness of educational intervention based on transtheoretical model in promoting oral health self-care behaviors among elementary students. J Isfahan Dent Sch. 2013;9(1):37-49.

22. Peyman N, Samiee Roudi K. The effect of education based on the theory of planned behavior on caries prevention of permanent teeth in fifth grade students in Khaf city. Journal of Mashhad Dental School. 2015;39(2):123-36.

23. N HR, T A, Y K, F Z, M S. Development of an Occupational Cognitive Failure Questionnaire (OCFQ): Evaluation validity and reliabilit. Iran Occupational Health. 2012;9(1):29-40. 
24. Darren George pM. SPSS for Windows Step by Step: A Simple Guide and Reference Allyn \& Bacon. 2003.

25. MOHAMMADI ZI, Yekaninejad M, Akaberi A, Pakpour A. The effectiveness of Motivational interviewing (MI) of oral self care behaviors among high school students in Qazvin. 2013.

26. Jürgensen N, Petersen P. Promoting oral health of children through schools-Results from a WHO global survey 2012. Community Dent Health. 2013;30(4):204-18.

27. M HA, D V, K P. Evaluation of knowledge and plaque scores in school children before and after health education. Dental Research Journal. 2011;8(4):189-96.

28. HA GA, SH N, M H. Efficacy of Educational Film for Enhancing Oral Health Knowledge, Attitude and Performance of Elementary Students. JDS. 2014;32(4):197-201.

29. Hebbal M, Ankola AV, Vadavi D, Patel K. Evaluation of knowledge and plaque scores in school children before and after health education. Dental research journal. 2011;8(4):189.

30. M M, F J, M BM, N H, F Z, N D. Knowledge, Attitude and Practice of Elementary Schools Students about Oral Health in Yazd. Iranian Journal Pdiatric Dentistry. 2013;9(1):43-50.

31. R K, H G, T M, A K. Health Education in Primary School Textbooks in Iran in School Year 2010-2011. Journal of Dentistry, Tehran University of Medical Sciences 2014;11(5):536-44.

32. N ST, A K, Singh G. Impact evaluation of two methods of dental health education among children of a primary school in rural India. Medical Journal of Dr DY Patil University. 2016;9(1):66-71.

\section{Tables}

Table 1. Educational content and methods of training sessions in the case group 


\begin{tabular}{|c|c|c|}
\hline Session & Topic & $\begin{array}{l}\text { Training } \\
\text { method }\end{array}$ \\
\hline One & $\begin{array}{l}\text { Primary information about dental and oral health and } \\
\text { attitude: Definition of oral health, the importance of oral } \\
\text { hygiene, the role and use of teeth, tooth structure, number } \\
\text { and types of teeth, how tooth decay, factors affecting dental } \\
\text { health, ways to prevent tooth decay, how to use toothbrushes } \\
\text {, how to use dental floss and mouthwash, time to see a } \\
\text { dentist }\end{array}$ & $\begin{array}{l}\text { Film, } \\
\text { photographic } \\
\text { slides, } \\
\text { educational } \\
\text { booklet, } \\
\text { question and } \\
\text { answer }\end{array}$ \\
\hline $\begin{array}{l}\text { Two } \\
\text { Self care }\end{array}$ & $\begin{array}{l}\text { Assessing oral and dental health, self-care: determining the } \\
\text { objectives, setting a timetable, learning necessary skills, } \\
\text { the importance of brushing to remove dental plaque, the } \\
\text { definition of plaque and how tooth decay, the frequency of } \\
\text { brushing, the duration of brushing, choosing the right } \\
\text { toothbrush and toothpaste, how to use floss, useful and } \\
\text { harmful foods to teeth in the form of an animation }\end{array}$ & $\begin{array}{l}\text { Group } \\
\text { discussion, } \\
\text { lecture, } \\
\text { animation }\end{array}$ \\
\hline $\begin{array}{l}\text { Three } \\
\text { Behavior: }\end{array}$ & $\begin{array}{l}\text { Brushing technique, use of dental floss and mouthwash, diet, } \\
\text { healthy life style, etc } \\
\text { In order to assess the level of performance of students and } \\
\text { identify their weaknesses, three students were asked to show } \\
\text { how to brush and use dental floss. Then, the correct use of } \\
\text { toothbrush was taught on the model. Based on the students' } \\
\text { learning, toothbrushes and toothpaste were distributed } \\
\text { among the students. To keep the behavior going, students } \\
\text { were asked to check each time they brushed their teeth in the } \\
\text { behavior chart. In the next step, how to use dental floss was } \\
\text { taught, and virtually every student was taught with the } \\
\text { distribution of floss. } \\
\text { After the reception, a group game "Saying on the phone" was } \\
\text { held to draw the students' attention and remind them of the } \\
\text { contents of the previous session. In this way, the set goals of } \\
\text { oral care and the desired activities were repeated in the form } \\
\text { of sentences and in the form of games. In this way, the } \\
\text { students were divided into two groups and placed in two } \\
\text { rows. The first person in each group was called a sentence, } \\
\text { and this sentence had to be repeated slowly in the next } \\
\text { person's ear, respectively, and the last person had to say the } \\
\text { sentence completely and correctly to the instructor. Each } \\
\text { group did this faster and won the game. In the next step, the }\end{array}$ & $\begin{array}{l}\text { Practical } \\
\text { education, } \\
\text { game, } \\
\text { animation }\end{array}$ \\
\hline
\end{tabular}




\begin{tabular}{|c|c|c|}
\hline & $\begin{array}{l}\text { use of mouthwash was explained and the mouthwash was } \\
\text { practically used and the animation was displayed. Proper use } \\
\text { of toothbrushes, floss and mouthwash was shown in } 5 \\
\text { minutes with animation. }\end{array}$ & \\
\hline $\begin{array}{l}\text { Four } \\
\text { Self- } \\
\text { efficacy }\end{array}$ & $\begin{array}{l}\text { In addition to educational animation, games were used to } \\
\text { practice oral and dental health skills in different situations } \\
\text { like tiredness, disease, party, etc. } \\
\text { Skills were learned in a variety of situations including time of } \\
\text { fatigue, illness, lack of toothbrushes, and playing and } \\
\text { attending a party were performed by the students themselves } \\
\text { in a pantomime format so that the activity was performed by } \\
\text { one student and the rest. They guessed what the situation was } \\
\text { and expressed their views on the situation. Also, the student } \\
\text { behavior chart was reviewed a week ago, and the } \\
\text { importance of behavior behavior was recalled, and students } \\
\text { were asked to find ways to recall behavior by conducting } \\
\text { group discussions, and at the end of the discussion, repetitive } \\
\text { topics were removed and final comments such as "Let's ask } \\
\text { Dad and Mom to remind us" or "Put a toothbrush picture on } \\
\text { the wall of the room." The animation was then displayed. The } \\
\text { animation showed the importance of permanent teeth, the } \\
\text { important of six teeth, fluoride therapy and fissure sealant, } \\
\text { seeing a dentist and emphasizing the regular use of } \\
\text { toothbrushes and toothpaste in } 3 \text { minutes. Also, it was handed } \\
\text { over to the students to see with the family in order to repeat } \\
\text { the lessons at home and the family's access to the educational } \\
\text { materials of the CD animation. }\end{array}$ & $\begin{array}{l}\text { Animation, } \\
\text { game, group } \\
\text { discussion }\end{array}$ \\
\hline
\end{tabular}

Table 2. Frequency distribution of qualitative demographic variables in the case and control groups 


\begin{tabular}{|c|c|c|c|c|c|c|}
\hline \multirow[t]{2}{*}{ Group } & \multirow[b]{2}{*}{ Variable } & \multicolumn{2}{|l|}{ Case } & \multicolumn{2}{|l|}{ Control } & \multirow[t]{2}{*}{$\mathrm{p}-\mathrm{v}$} \\
\hline & & Number & $\%$ & Number & $\%$ & \\
\hline \multirow[t]{3}{*}{$\begin{array}{l}\text { Father's } \\
\text { education }\end{array}$} & $\begin{array}{l}\text { Primary school and Junior } \\
\text { high school }\end{array}$ & 7 & 18.4 & 9 & 20.5 & \multirow[t]{3}{*}{0.965} \\
\hline & $\begin{array}{l}\text { High school diploma and } \\
\text { associate degree }\end{array}$ & 19 & 50.00 & 22 & 50.00 & \\
\hline & Bachelor's degree and higher & 12 & 31.6 & 13 & 19.5 & \\
\hline \multirow[t]{3}{*}{$\begin{array}{l}\text { Mother's } \\
\text { education }\end{array}$} & $\begin{array}{l}\text { Primary school and Junior } \\
\text { high school }\end{array}$ & 6 & 15.8 & 11 & 23.3 & \multirow[t]{3}{*}{0.458} \\
\hline & $\begin{array}{l}\text { High school diploma and } \\
\text { associate degree }\end{array}$ & 22 & 57.9 & 26 & 60.5 & \\
\hline & Bachelor's degree and higher & 10 & 26.3 & 7 & 16.3 & \\
\hline \multirow[t]{3}{*}{ Birth Rank } & First & 15 & 39.5 & 26 & 59.1 & \multirow[t]{3}{*}{0.207} \\
\hline & Second & 15 & 39.5 & 12 & 17.3 & \\
\hline & Third or higher & 8 & 21.05 & 6 & 13.6 & \\
\hline \multirow[t]{2}{*}{ Gender } & Girl & 22 & 57.9 & 20 & 45.5 & \multirow[t]{2}{*}{0.184} \\
\hline & Boy & 16 & 42.1 & 24 & 54.5 & \\
\hline
\end{tabular}

Table 3. Frequency distribution of quantitative demographic variables in the case and control groups

\begin{tabular}{|c|c|c|c|c|c|}
\hline & Group & Number & $\%$ & Standard deviation & $\mathrm{p}-\mathrm{v}^{* *}$ \\
\hline \multirow{2}{*}{ Number of family members } & Control & 44 & 3.93 & 0.9 & 0.533 \\
\cline { 2 - 6 } & Case & 38 & 4.05 & 0.8 & \\
\hline \multirow{2}{*}{ Age } & Control & 44 & 9.64 & 1.9 & 0.424 \\
\cline { 2 - 6 } & Case & 38 & 9.39 & 1.8 & \\
\hline
\end{tabular}

Table 4. Mean scores of variables before and after intervention in the case and control groups 


\begin{tabular}{|c|c|c|c|c|c|c|}
\hline \multirow[t]{2}{*}{ ariable } & \multirow[t]{2}{*}{ Time } & \multicolumn{2}{|c|}{$\begin{array}{l}\text { Before } \\
\text { intervention }\end{array}$} & \multicolumn{2}{|c|}{$\begin{array}{l}\text { Five months after } \\
\text { intervention }\end{array}$} & \multirow[t]{2}{*}{$\begin{array}{l}\text { p-value } \\
\text { Wilcoxon }\end{array}$} \\
\hline & & Mean & SD & Mean & SD & \\
\hline \multirow[t]{3}{*}{ elf-care } & Case & 3.8 & 0.96 & 4.8 & 0.3 & $<0.001$ \\
\hline & Control & 4.2 & 1.1 & 4.2 & 0.89 & 0.527 \\
\hline & $\begin{array}{ll}\text { p-value } & \text { Mann } \\
\text { Whitney } & \\
\end{array}$ & \multicolumn{2}{|l|}{0.057} & \multicolumn{2}{|l|}{0.002} & \\
\hline \multirow[t]{3}{*}{ nowledge } & Case & 6.7 & 2.5 & 9.4 & 0.9 & 0.001 \\
\hline & Control & 6.2 & 2.3 & 6.7 & 2.1 & 0.004 \\
\hline & $\begin{array}{l}\text { p-value Mann } \\
\text { Whitney }\end{array}$ & \multicolumn{2}{|l|}{0.253} & \multicolumn{2}{|c|}{$<0.001$} & \\
\hline \multirow[t]{4}{*}{ ttitude } & Case & 55.1 & 12.5 & 61.5 & 4.8 & $<0.001$ \\
\hline & Control & 54.02 & 14.7 & 55.06 & 11.4 & 0.897 \\
\hline & $\begin{array}{l}\text { p-value Mann } \\
\text { Whitney }\end{array}$ & \multicolumn{2}{|l|}{0.627} & \multicolumn{2}{|c|}{$<0.001$} & \\
\hline & & & & & & $\begin{array}{l}p \text {-value paired } \\
\text { t- test }\end{array}$ \\
\hline \multirow[t]{3}{*}{ ehavior } & Case & 17.07 & 5.61 & 21.21 & 5.07 & $<0.001$ \\
\hline & Control & 18.2 & 5.87 & 17.97 & 5.55 & 0.142 \\
\hline & $\mathrm{p}$-value $\mathrm{t}$ - test & \multicolumn{2}{|l|}{0.343} & \multicolumn{2}{|l|}{0.008} & \\
\hline \multirow{3}{*}{$\begin{array}{l}\text { elf- } \\
\text { :ficacy }\end{array}$} & Case & 36.8 & 11.6 & 48.9 & 10.8 & $<0.001$ \\
\hline & Control & 42.11 & 15 & 41.93 & 14.9 & 0.543 \\
\hline & $\mathrm{p}$-value $\mathrm{t}$ - test & 0.089 & & 0.019 & & \\
\hline
\end{tabular}

\section{Supplementary Files}

This is a list of supplementary files associated with this preprint. Click to download.

- hashemiconsort.doc

- questionnaireoralhealth.doc 